\title{
MICHEL DE MONTAIGNE E AS DIRETRIZES DE UMA EDUCAÇÃO PARA A AUTONOMIA
}

\author{
MICHEL DE MONTAIGNE ET LES LIGNES DIRECTRICES D'UNE ÉDUCATION POUR \\ L'AUTONOMIE
}

\author{
João Batista Andrade Filho'
}

\begin{abstract}
Resumo: Michel de Montaigne (1533 - 1592) foi um ilustre filósofo francês do período da Renascença. Portanto, viveu em um mundo em transição, rumando na direção do que convencionalmente passou a ser chamado de Modernidade. O momento histórico no qual está inserida sua biografia caracteriza-se por conflitos e perturbações sociais e políticas, bem como por descoberta de um novo mundo e avanços no conhecimento, reflexo de uma busca por desenraizamento de uma tradição medieval e pela construção de uma nova mentalidade pautada pela autonomia em relação aos ditames escolásticos. Montaigne herdou esse ímpeto e propôs uma filosofia humanista da qual deriva uma proposta educativa. Elaboramos o presente artigo com o intuito de colher diretrizes para o ensino de filosofia no Ensino Médio a partir do conceito de autonomia tão bem trabalhado pelo autor em questão. Inicialmente, partimos do estudo do texto Montaigne: filosofia e educação para a vida, do professor Márcio Silveira Lemgruber (2015). Posteriomente, aprofundamos a interpretação com o texto contido nos Ensaios, A educação da criança, reforçado com textos de outros autores como Cambi (1999) e Morandi (2002), bem como com o texto das Orientações Curriculares Nacionais (MEC, 2006), referente ao ensino de filosofia.
\end{abstract}

Palavras-chave: Montaigne; educação; autonomia; ensino de filosofia

Résumé: Michel de Montaigne (1533 - 1592) était un illustre philosophe français de la période de la Renaissance. Il a donc vécu dans un monde en transition, dans la direction de ce que l'on appelait traditionnellement la modernité. Le moment historique dans lequel sa biographie est insérée est caractérisé par des conflits et des perturbations sociales et politiques, ainsi que par la découverte d'un monde nouveau et des avancées dans la connaissance, reflet d'une recherche par déraciné d'une tradition médiévale et par la construction d'une nouvelle mentalité guidé par l'autonomie par rapport aux diktats scolastiques. 
Montaigne a hérité de cet élan et a proposé une philosophie humaniste à partir de laquelle une proposition éducative a été élaborée. Nous développons le présent article dans l'intention de rassembler des directives pour l'enseignement de la philosophie au lycée à partir du concept d'autonomie si bien travaillé par l'auteur en question. Nous partons du texte de Montaigne: philosophie et éducation pour la vie, du professeur Márcio Silveira Lemgruber. Plus tard, nous avons élaboré le texte avec celui contenu dans les essais, L'éducation de l'enfant, renforcé avec des textes d'autres auteurs tels que Cambi (1999) et Morandi (2002), ainsi qu'arec le texte des Directives curriculaires nationales (MEC, 2006). à l'enseignement de la philosophie.

Mots-clés: Montaigne, éducation; autonomie; enseignement de la philosophie

\section{INTRODUÇÃO}

O século XVI, notadamente na Europa, representa um período conturbado em muitos sentidos. É uma época de transformações que dão corpo à denominada Modernidade. E sua conturbação se deu sob muitos e complexos acontecimentos que promoveram uma ruptura dramática na estrutura da sociedade que, segundo Cambi (1999, p. 196), invadiram o campo político, religioso e cultural em geral. Sob o ponto de vista religioso, foi palco das investidas de Martinho Lutero (1483 - 1546) que provocaram o cisma na Igreja Católica. Igualmente turbulento em virtude da nova maneira de pensar o universo que promoveu uma reviravolta científica deflagrada por Nicolau Copérnico (1473 - 1543), com seu De Revolutionibus Orbium Coelestium, cujas ideias, mais tarde, foram confirmadas e desenvolvidas por Galileu Galilei (1564 - 1642), cujo empenho pelo desenvolvimento da Ciência teve como corolário a formatação de um método científico mais adequado com a nova visão de mundo gestada.

Além disso, as efetividades sociais, políticas e econômicas das aspirações da burguesia em ascensão, que promoveram rupturas na mentalidade feudal, substituindo a unidade de produção agrária pela manufatura e comércio, ganharam impulsionamento com o domínio das técnicas de navegação oceânica que permitiram a conquistas de terras e riquezas até então inimagináveis. Isso impulsionou a sociedade na direção da sedimentação das Monarquias Absolutistas como regime político que deu a auferida autonomia que derrubou o ímpeto do senhorio medieval. Tal regime, propiciador da centralização do poder político, que encontrou fundamentação nos escritos de Nicolau Maquiavel (1469 - 1527).

As referidas investidas aconteciam como um conjunto de aspirações que procuravam promover rupturas a partir da negação do princípio de autoridade medieval. Liberdade de pensar e agir sem a tutela de uma autoridade. A partir disso, formatava-se, portanto, uma mentalidade alimentadora de autonomia que reverberou no pensamento filosófico, cujo desenrolar teve por ápice, posteriormente, o movimento iluminista, no século XVIII.

Liberdade de pensamento, autonomia para o pensar. É nesse contexto que está inserido Michel de Montaigne. É daí que se nutrem suas reflexões filosóficas, expressando os princípios de um novo modo de vida. Segundo Chauí (1996, p.10), "Montaigne viveu numa época extremamente conturbada, da qual refletiu algumas características fundamentais, especialmente as mais contraditórias." Nos Ensaios encontramos uma orientação sobre educação que bem poderia ser a síntese das diretrizes do pensamento do autor.

Notadamente, enfocaremos aqui o ensaio Sobre a Educação da Criança, de Michel de 
Montaigne (1996), presente na primeira parte de seu Ensaios, publicado em 1850², no qual o autor expõe as diretrizes de uma educação voltada para um aprendizado baseado nas coisas cotidianas, livre de uma cultura meramente livresca, desprendida do poder de autoridade conforme o que predominava no modelo escolástico, e, portanto, construída no sentido de uma autonomia que, segundo o próprio filósofo, "não é mais segundo Platão, do que segundo eu mesmo, que tal coisa se enuncia desde que a compreendamos e a vejamos da mesma maneira." (MONTAIGNE, 1996, vol. I, p. 152). Uma educação, indicação conforme ainda nos diz o mesmo, "que não lhe peça conta apenas das palavras da lição, mas também do seu sentido e substância, julgando do proveito, não pelo testemunho da memória e sim pelo da vida." (MONTAIGNE, 1996, vol. I, p. 151)

Confirmada, portanto, uma ideia de uma educação voltada para a vivência e que reflita sobre questões práticas do cotidiano, pautaremos nossa interpretação no artigo do professor Márcio Silveira Lemgruber (2015), intitulado Montaigne: filosofia e educação para a vida, a fim de que seja possível pensar uma didática para o ensino de filosofia no ensino médio que remonte inclusive aos tempos socráticos da filosofia, ensinando os alunos a fazerem boas perguntas, fundamentadas na ideia de "indagar quem sabe melhor e não de quem sabe mais." (MONTAIGNE 1996. p. 140 apud. LEMGRUBER, 2015. p. 157).

Não estando afeito às longas e incansáveis reflexões metafísicas, os jovens alunos de ensino médio encontrarão excelente oportunidade de iniciar na vida filosófica com as bem elaboradas reflexões de Michel de Montaigne, dado que podem muito bem servir ao propósito de despertá - los a partir da realidade mais imediata possível, aquela na qual se insere e da qual não compreende os mecanismos, e da qual jamais imaginaria pensá-la filosoficamente.

O professor de filosofia poderá encontrar em Montaigne não apenas as reflexões filosóficas propriamente ditas, mas, sobretudo, um método para o filosofar, e, desta feita, poderá aliá-lo à natural tendência à contestação inquietante dos jovens que estão em um momento de conflitos internos, de incertezas, ávidos por respostas, e, por isso mesmo, necessitados dos exercícios do ver-rever, ouvir-reouvir, pensar-repensar. Afinal, a realidade é complexa para nos firmarmos em um único ponto em definitivo. Assim, será imprescindível ao jovem, a partir de um esforço didático no ensino de filosofia, entender a máxima utilizada por Montaigne (1996): "não menos que saber, duvidar me apraz."3

O presente artigo, nascido de inquietações de leituras sobre o ensino de filosofia, bem como de minha própria prática escolar, foi elaborado com o objetivo de colher diretrizes no âmbito da referida disciplina, na modalidade do Ensino Médio. Para tanto, elegemos o conceito de autonomia, por considerá-lo muito bem delineado pelo autor em questão, e caro quanto à expectativa de uma educação para o pensar.

Imprimindo uma abordagem compreensiva, inicialmente partimos do estudo do texto Montaigne: filosofia e educação para a vida, do professor Márcio Silveira Lemgruber (2015). Posteriomente, aprofundamos a interpretação com o texto contido nos Ensaios, A educação da criança, reforçado com textos de outros autores como Cambi (1999) e Morandi (2002), bem como com o texto das Orientações Curriculares Nacionais (MEC, 2006), referente ao ensino da filosofia.

\section{IDEIA DE UMA EDUCAÇÃO COMO CONSTRUÇÃO PARA O PENSAMENTO AUTÔNOMO}

O eminente intelectual, ao qual estamos nos reportando, foi um filósofo gestado em um mundo em transição, conforme já detalhado na introdução deste texto. Sua filosofia, portanto, refletiu também essa intenção por afirmação. Assim como seu mundo era um mundo por descobrir-se, ou seja, em processo de formatação social, assim também foi o indivíduo Michel de Montaigne (1996), conforme é possível depreender da citação abaixo:

2 A informação consta no volume I do Ensaios, publicado pela Nova Cultural no ano de 1996, p. 23.

3 DANTE apud MONTAIGNE, 1996, Vol. I, p. 152. 
Exponho aqui meus sentimentos e opiniões, dou-os como os concebo e não como os concebem os outros; meu único objetivo é analisar a mim mesmo e o resultado dessa análise pode, amanhã, ser bem diferente do de hoje, se novas experiências me mudarem. (MONTAIGNE, 1996, vol. I, p. 149).

O referido filósofo francês buscou rememorar ou, melhor dizendo, fez a busca da recomposição de uma tradição na história da filosofia que remonta à prática filosófica de Sócrates, fundamentada no auto-exame, expresso este na máxima délfica do "conhece-te a ti mesmo". Assim é que, para Montaigne, segundo Chauí (1996, vol. l, p. 15), "o centro de toda problemática do conhecimento e, consequentemente, de toda filosofia não é, portanto, o mundo, mas o homem."

E este pouco sabe de si mesmo. Perguntando-se a si próprio sobre sua essência, constata um cerco de coisas insólitas. Tudo o que vê parece estranho e bizarro. Tanto as coisas próximas, pelas quais passa sem deter-se, quanto as distantes e relatadas pelos outros. Aquilo que toma por real não é mais que uma parcela do possível. Como pode pretender que isto aqui exista e aquilo ali não? Colocado diante do desconhecido, diante de um mundo de maravilhas, no qual se acha implicado, sem poder decifrá-lo, o homem procura refúgio em si mesmo e na própria vida, essa coisa que the surge sempre como um dado presente.(CHAUÍ, 1996, p. 15)

Porém, conforme lembra Lemgruber (2015, p. 153), Montaigne "[...] constrói uma sabedoria a partir do exame de sua vida cotidiana, adotando a estratégia de falar do humano tendo como base um homem, mais precisamente, ele próprio".

Conforme palavras do próprio autor dos Ensaios:

Apresento uma vida das mais vulgares, que nada tem de especial. A vida íntima do homem do povo é de resto um assunto filosófico e moral tão interessante quanto a do indivíduo mais brilhante; deparamo-nos em qualquer homem com o Homem. (MONTAIGNE4, apud. LEMGRUBER, 2015, p. 153).

Foi este homem, em busca de si e de suas vicissitudes, portanto, por entender-se, e assim tentar compreender um pouco mais do que seja o humano, que, de maneira presentificada, lançou luz sobre aspectos de uma educação que, conforme Cambi (1999, p. 269), "[...] tem o dever de formar homens de mentalidade crítica, aberta, e de sólidos princípios morais."

A compreensão do conceito de educação advindo das reflexões de Montaigne, conforme a referência acima, só se torna possível com a apreensão do conceito de autonomia, pois foi a partir deste que o filósofo teceu a crítica ao sistema de educação vigente, uma educação "retoricista", que primava pela "prolixidade" e o "esbanjamento de fórmulas servis". (LEMGRUBER, 2015, p. 156).

Porém, a fonte alimentadora do conceito de autonomia em Montaigne reside na mentalidade do voltar-se a si mesmo do homem. Pois, conforme ele mesmo afirmava, estudava a 
si mesmo mais do que a qualquer outra coisa e, portanto, aí estaria sua metafísica e sua física. (MONTAIGNE apud MONDIN, 1982, p. 20).

Segundo Morandi (2002, p. 31), Montaigne retrata a ruptura com uma educação que "embrutece os espíritos" e escolhe "um condutor que tenha a cabeça antes bem feita do que bem cheia".

É isso que o faz precursor da pedagogia moderna, a rejeição da educação como transferência de conteúdos a serem memorizados. A imagem de que Montaigne faz uso para representar tal concepção de ensino - "cabeças de pote" - sugere um recipiente onde algo é depositado. A idéia do depósito estará, séculos adiante, na metáfora freireana da "educação bancária". Também antecedendo Freire, em seu "pensar certo", Montaigne afirma que "cumpre, entretanto, indagar quem sabe melhor e não quem sabe mais" (...), ou seja, que é melhor ter uma cabeça bem formada do que exageradamente cheia. (LEMGRUBER, 2015, p. 156)

Segundo Montaigne, a educação adequada deve primar pela preparação do próprio indivíduo para a vida e, segundo ele mesmo anunciara, "certamente tornaremos a criança servil e tímida se não lhe dermos a oportunidade de fazer algo por si." (MONTAIGNE, 1996, vol. I, p. 153). O conceito de autonomia reside no fato de que o "o aluno não deve receber um saber pronto para tão somente decorar, mas que seja instigado a buscar o conhecimento e realizar uma produção própria". (LEMGRUBER, 2015, p. 157).

No ensaio Sobre a educação da criança, o filósofo buscou atender ao clamor de uma jovem senhora chamada Diana de Foix, e, ao que indica o mesmo, ela, prestes a ser mãe, já antecipadamente demonstrava preocupação com a educação do pretenso varão, pois é assim como se referiu o filósofo ${ }^{5}$ em relação à esperada criança.

Assim, pautado na própria experiência, Montaigne a aconselhou que o método do preceptorado seria a condição adequada para a formação da criança. Evitaria-se, assim, em primeiro lugar, a rudeza da instituição escolar, pois, segundo ele mesmo depõe:

A disciplina da maior parte de nossos colégios sempre me desagradou. Menos prejudiciais seriam talvez se a inclinassem para a indulgência. São verdadeiras prisões para cativeiro da juventude, e a tornam cínica e debochada antes de o ser. Ide ver esses colégios nas horas de estudo: só ouvireis gritos de crianças martirizadas e de mestres furibundos. Linda maneira de acordar o interesse pelas lições nessas almas tenras e tímidas, essa de ministrá-las carrancudo e de chicote nas mãos! Que método iníquo e pernicioso! (MONTAIGNE, 1996, vol. I, p. 164).

Em segundo lugar, do mesmo modo condenou, pela aquiescência, a educação doméstica. De qualquer maneira, ambas estão cheias de vícios e são desencaminhadoras daquela fina-

5 Como pode ser lido às páginas 149-150: "Alguém, depois de ler o ensaio precedente, dizia há tempos em minha casa que eu me devia ter alongado um pouco mais sobre a educação das crianças. Mas senhora, se eu tivesse alguns conhecimentos do assunto não os empregaria melhor do que em fazendo presente deles a esse rapazinho que ameaça sair de vós (sois generosa demais para não começardes por um varão), pois tendo tomado tão grande parte na preparação de vosso casamento, tenho algum direito de me interessar pela grandeza e prosperidade de tudo o que dele provier. Por outro lado, os antigos privilégios que tendes sobre mim, levam-me naturalmente a desejar honras, bens e melhorias em tudo o que vos diz respeito. Mas na realidade disso só entendo que a maior e mais importante dificuldade da ciência humana parece residir no que concerne à instrução e à educação da criança." (MONTAIGNE, 1996, vol. I, p. 149-150) 
lidade precípua da educação, que é a autonomia, conforme já mencionado.

Diante de efusiva crítica aos métodos instituídos, então, o próprio filósofo definiu as diretrizes de seu modelo educacional, conforme se lê no trecho abaixo.

Quero que a delicadeza, a civilidade, as boas maneiras se modelem ao mesmo tempo que o espírito, pois não é uma alma somente que se educa, nem um corpo, é um homem: cabe não separar as duas parcelas do todo. (...) Seja como for, a essa educação deve proceder-se com firmeza e brandura e não como é de praxe, pois, como o fazem atualmente, em lugar de interessarem os jovens nas letras, desgostam-nos pela tolice e a crueldade. Deixem-se de lado a violência e a força: nada a meu ver abastarda mais e mais embrutece uma natureza generosa. (MONTAIGNE, 1996, vol. I, p. 164).

Para Montaigne, essa educação para tal fim proporcionaria ao aluno, além de formação moral, pois "... formar-lhe-á a vontade para que sirva seu príncipe com lealdade, afeição e coragem, mas o desviará de se prender a ele senão por dever cívico." (MONTAIGNE, 1996, vol. l, p. 155). Da mesma forma, favoreceria uma formação atenta e experiencialmente vivida, donde seria possível incutir-lhe no espírito uma honesta curiosidade por todas as coisas de forma a registrar tudo o que haja de singular à sua volta. (MONTAIGNE, 1996, vol. I, p. 156).

Este mundo tão grande, que alguns ampliam ainda como as espécies de um gênero, é o espelho em que nos devemos mirar para nos conhecermos de maneira exata. Em suma, quero que seja esse o livro do nosso aluno. A infinita diversidade de costumes, seitas, juízos, opiniões e leis ensinam-nos a apreciar sadiamente os nossos, a reconhecer suas imperfeições e fraquezas naturais, o que já não é pouco. (MONTAIGNE, 1996, vol. I, p. 156)

A proposta de Montaigne, portanto, residiria numa pedagogia da autenticidade, dado que, a partir de reflexões próprias, atentas e constantes, o indivíduo não se torne gaiola de si mesmo.

\section{APORTES DIDÁTICOS PARA AULAS DE FILOSOFIA NO ENSINO MÉDIO}

Chegar ao conhecimento de si. Este é um propósito socrático que Montaigne perseguiu, mas que o procurou aliando-o a uma certa pitada da compreensão cética, à luz de Pirro de Elis (360 - 270 a. C.), que colocava em suspeição qualquer tentativa de absolutizar respostas, negando toda possibilidade de o homem atingir conhecimentos estáveis e definitivos. Nenhuma pura objetividade, nada em definitivo, poderia constituir a marca do conhecimento humano.

O conhecimento humano encerra-se dentro dos próprios limites do sujeito pensante e nada comunica de seguro sobre a natureza das coisas, nem sobre o próprio homem. Igualmente impossível é formular um conjunto de preceitos éticos com validez objetiva. Assim como as sensações nada descobrem dos objetos externos, também os valores, 
aparentemente inerentes às coisas, reduzem-se a reflexões do sujeito, e nada é bom ou mau 'em si'. (...) Os princípios da moral desfazem-se como espuma e só restaria ao homem voltar-se para si mesmo e tentar encontrar um ponto fixo de equilíbrio e quietude, subtraído às transformações das coisas externas. (CHAUí, 1996, p. 16).

Partindo do pressuposto e do estabelecimento de uma reflexão atenta e constante, e compreendendo que nenhuma resposta pudesse ser única, de maneira a encerrar a procura, Montaigne expressou uma filosofia que se pautou em questões humanas mais imediatas e, portanto, que estavam em constante diálogo: primeiro do si consigo mesmo, depois, deste com o mundo, colocando nossas certezas à prova em um constante exercício.

Conforme ele mesmo constatou e alertou a respeito daquilo que encaixamos como certezas, é a força do hábito a responsável por tal encaixotamento.

O principal efeito da força do hábito reside em que se apodera de nós a tal ponto que já quase não está em nós recuperar-nos e refletirmos sobre os atos a que nos impele... e imaginamos que as ideias aceitas em torno de nós, e infundidas em nós por nossos pais, são absolutas e ditadas pela natureza. Daí pensarmos que o que está fora dos costumes está igualmente fora da razão. (MONTAIGNE, 1996, v.l, apud. LEMGRUBER, 2015, p.161)

Há nesta compreensão, portanto, diretrizes essenciais e urgentes para as aulas de Filosofia no Ensino Médio. Primeiramente, pelo estabelecimento do diálogo como metodologia de aulas, abrindo a possibilidade de conduzir os jovens à disciplina do saber falar e ouvir, atributos tão intensamente imprescindíveis nos nossos dias. Depois, pela autodisciplina, notadamente ao fortalecer nos alunos uma constante prática inquiridora de si mesmos, daquilo que fazem, e pensam, fazendo-os questionar posições tomadas ou crenças abraçadas, e revendo aquilo que merece passar por revista.

O ensino deve ser ministrado ora por conversas ora por leituras; ora o preceptor the apresentará o próprio texto do autor mais adequado ao fim da educação, ora lhe fornecerá somente o miolo, a substância. (...)... No nosso método a alma acha a que se apegar, com que se alimentar. O que dele tirar o jovem será maior e mais depressa amadurecerá. (MONTAIGNE, 1996, p. 159-160).

O pensamento de Montaigne, nesse sentido, encerra uma atualidade quanto à posição da filosofia no ensino e quanto ao que esta pode proporcionar a um mundo cada vez mais diverso e carente de compreensão de sua complexidade, ávido pelo estabelecimento de um diálogo que permita a boa convivência, superando posições que conduzem aos extremismos e que forçosamente levam aos credos fundamentalistas, sendo estes, propriamente, religiosos ou mesmo políticos.

O trecho abaixo revela aspectos dessa atualidade da filosofia conforme relatado acima. 
valor, na teoria como na prática. Creio que isso se deve aos raciocínios capciosos e embrulhados com que the atopetaram o caminho. Faz-se muito mal em pintar como inacessivel aos jovens, e em the emprestar uma fisionomia severa, carrancuda e temível. Quem Ihe pôs a máscara falsa, lívida, hedionda? Pois não há nada mais alegre, mais vivo e diria quase mais divertido. Tem ar de festa e folguedo. Não habita onde haja caras tristes e enrugadas. (MONTAIGNE, 1996, p. 160).

A filosofia segundo Montaigne, fala a linguagem do jovem, que se caracteriza por ser irrequieta e alegre, arguta, estampando uma curiosidade e avidez pelo conhecimento. Em dosagens bem administradas, levando-se em conta o ritmo do aluno e as especificidades de cada um, poderia ser elemento articulador de saberes.

Assim, professor da disciplina, compreendendo o caráter interdisciplinar da filosofia, deve entender que suas aulas devem abranger uma infinita gama de conhecimentos, pois destes devem derivar os mais elaborados questionamentos. Isso se constituiria em um forçoso convite para que se mergulhe em temas relacionados à arte e à cultura de uma maneira geral e, notadamente, ligados à literatura, ficcional ou não ficcional, e ao cinema, bem como à ciência, e, fundamentalmente, àquelas questões mais imediatas e urgentes que compõem o universo cotidiano dos jovens.

Se a filosofia é parte da essência humana e as reflexões filosóficas têm origem na vida, a atual distância entre filosofia e o cotidiano das pessoas é descabida. Por isso, parte da tarefa do professor deve ser chamar a atenção do aluno para a proximidade entre o ser humano, a filosofia e a vida. Se a filosofia se banha nas águas da sociedade, da cultura e do conhecimento humano, e a tudo pode indagar para desenvolver reflexões, não tem sentido torná-la um instrumento técnico isolado do mundo e dos outros conhecimentos. (MELANI, 2016, p. 404)

É, aliás, uma compreensão bem próxima daquela que Schoppenhaver (1960) escreveu em seu A necessidade metafísica, onde afirmou que ter espírito filosófico "é ser capaz de admirar-se dos acontecimentos habituais e cotidianos, é ser capaz de propor-se como objeto de reflexão o que há de mais geral e de mais comum." (SCHOPPENHAUER, 1960, p. 85 apud MELANI, 2016, p. 403).

A necessidade da filosofia deve ser uma constante na vida humana, incluindo-se aí notadamente a vida dos jovens, conforme a máxima epicurista que prescreveu que "por moço que seja que ninguém se recuse a praticar a filosofia, e que os velhos não se cansem dela.."6

Quem procede de outro modo parece dizer que ainda não é tempo de viver feliz, ou que já o não é. Mas para tais ensinamentos não quero que prendam o jovem; não quero que o abandonem ao mau humor e à cólera de um mestre-escola furioso; não quero corromper-lhe o espírito torturando-o com trabalho, como o fazem a outros, catorze a quinze horas por dia, a exemplo de um carregador. Não acharia bom tampouco se, inclinado por temperamento para a solidão e a melancolia, e manifestando demasiado amor aos livros, Ihe incentivassem esse gosto; isto os torna inaptos para a vida da sociedade e os afasta

6 A frase é de Epicuro, citada por Montaigne nos Ensaios, vol. I, 1996, p. 162-163. 
de melhores ocupações. (MONTAIGNE, 1996, vol. l, p.163).

Montaigne sugeriu a filosofia como formadora da inteligência e dos costumes, com o "privilégio de se misturar a tudo", pois como ele mesmo reforça citando Cícero, "foi muito mais nos costumes do que nos escritos que os filósofos aprenderam a maior parte de todas as artes: a arte de bem viver". (MONTAIGNE, 1996, vol. I, p. 166).

Filosofar para viver melhor, pois, conforme as próprias palavras do filósofo em questão, "O verdadeiro espelho de nosso pensamento é a maneira de vivermos". (MONTAIGNE, 1996, vol. I, p. 166).

Assim, a aula de filosofia seria o ambiente de diálogos entre os estudantes, entre estes e o professor, bem como com os autores da filosofia e de outras áreas do saber, através mesmo de seus textos. Também seria locus dos questionamentos e do contraditório, do compartilhamento de dúvidas e do destronamento de certezas, onde pensamento e a linguagem, em uso adequado e significativo, promoveriam o jogo das ideias claras.

Acredito, e Sócrates o diz formalmente, que quem tem no espírito uma idéia clara e precisa sempre a pode exprimir, quer de um modo quer de outro, por mímica até, se for mudo: "Não falham as palavras para o que se concebe bem". Ora, como diz um outro, de modo igualmente poético embora em prosa: "Quando as coisas se assenhoram do espírito as palavras ocorrem", ou ainda: "As coisas atraem as palavras". (MONTAIGNE, 1996, vol. I, p. 167)

A filosofia de Montaigne abre oportunidades para aulas em sintonia com as Orientações Curriculares Nacionais que estabelecem também que à filosofia cabe o papel da contextualização sociocultural, da investigação e compreensão dos conhecimentos filosóficos articulados com as ciências, com as artes, exercitando a comunicação entre esses diversos saberes e diferentes compreensões acerca da realidade e da vida.

Se a Filosofia não é uma ciência (...) e tampouco uma das belas artes (...), ela sempre teve conexões íntimas e duradouras com os resultados das ciências e das artes. Ao dirigir o olhar para fora de si, no entanto, a Filosofia tem a necessidade, ao mesmo tempo, de se definir no interior do filosofar como tal, isto é, naquilo que tem de próprio e diferente de todos os outros saberes. (MEC, 2006. p. 22)

É nesta perspectiva do dirigir o olhar para fora de si, que faz da filosofia o instrumento educacional apropriado e possibilitante do posicionamento e do correlacionamento. Estes conceitos servem para expressar a natureza de saber formador e articulador da Filosofia, tão caros à genuína formação da cidadania do jovem estudante. Afinal, "os conhecimentos de Filosofia devem ser para ele vivos e adquiridos como apoio para a vida, pois do contrário dificilmente teriam sentido para um jovem nessa fase de formação." (MEC, 2006, p. 28).

\section{CONCLUSÃO}

O filósofo francês Michel de Montaigne buscou recompor uma tradição na história da filo- 
sofia fundamentada no autoexame expresso na máxima délfica do "conhece-te a ti mesmo" com a qual o próprio Sócrates havia iniciado sua vida e seu magistério filosófico. Para ele, o centro da problemática filosófica estaria no homem e nas coisas que o circundam e não em teorias repletas de palavrórios rebuscados e enigmáticas. Estas só afastariam o homem de suas reais circunstâncias.

Montaigne foi um homem em busca de si e de suas vicissitudes, procurando entender-se, e assim, acreditou na possibilidade de alcançar ou lançar luzes na compreensão um pouco mais detalhada do que seria o humano.

Portanto, a preocupação de sua filosofia estava na análise das circunstâncias presentes, refletindo o homem sobre si mesmo contextualizadamente. A prerrogativa do indivíduo autônomo, interprete de si, construtor do próprio pensamento, ganha centralidade na filosofia de Michel de Montaigne. Por isso mesmo, lançou diretrizes sobre aspectos de uma educação que tem a missão de formar homens com mentalidade crítica, aberta e com sólidos princípios morais.

A compreensão do conceito de educação advindo das reflexões de Montaigne, só se torna possível com a apreensão do conceito de autonomia, pois é a partir deste que o filósofo vai tecer a crítica ao sistema de educação vigente, uma educação que ele considerou meramente retórica, prolixa eliminadora da construção da autonomia humana.

Montaigne representou uma ruptura com uma educação que embrutecia os espíritos, que privilegiava os mais servis em detrimento dos mais capazes de pensar por si próprios. Sua filosofia mostra uma atualidade que muito bem atende as demandas de nosso tempo em relação à formação de jovens com espíritos reflexivos que não se deixem conduzir por novidades sedutoras.

A aula de filosofia no ensino médio seria o ambiente propriamente de diálogos bem como o locus de questionamentos e de contraditórios, do compartilhamento de dúvidas e do destronamento de certezas, num enriquecimento intelectivo promovendo o jogo das ideias claras e discursos bem afinados. Sintonizada com as Orientações Curriculares Nacionais, que estabelecem a filosofia com o papel de articuladores de conhecimentos e saberes, os Ensaios de Montaigne, por si já seriam suficientes para a formatação do plano de curso da disciplina.

\section{REFERÊNCIAS}

CAMBI, Franco. História da pedagogia. São Paulo: Fundação Editora da UNESP (FEU), 1999 - (Encyclopaideia).

CHAUÍ, Marilena. Montaigne: vida e obra. In. MONTAIGNE, Michel. Ensaios. Vol. I. Col.: Os Pensadores. Tradução de Sérgio Milliet. São Paulo: Editora Nova Cultural, 1996.

LEMGRUBER, Márcio Silveira (Org.). Montaigne: filosofia e educação para a vida. In: Educação in Foco. Juiz de Fora, v. 20, n. 2, p. 147-168, julho 2015/out. 2015.

MEC. Orientações curriculares nacionais. Vol. 3. Ciências humanas e suas tecnologias. Secretaria da Educação Básica. Brasilia: Ministério da Educação, 2006.

MELANI, Ricardo. Considerações sobre o ensino de filosofia. In: Diálogo: primeiros estudos em filosofia. V. único. 2 ed. São Paulo: Moderna, 2016. pp.403-415.

MONDIN, Batista. Curso de filosofia. Vol. 2. São Paulo: Edições Paulinas, 1981.

MONTAIGNE, Michel. Ensaios. Vol. I. Col.: Os Pensadores. Tradução de Sérgio Milliet. São Paulo: Editora Nova Cultural, 1996. 
MORANDI, Franc. Filosofia da educação. Bauru, SP: EDUSC, 2002.

SCHOPENHAUER, Artur. A necessidade metafísica. Belo Horizonte: Itatiaia, 1960.

SOBEL, Dava. Um céu mais perfeito: como Copérnico revolucionou o cosmo. São Paulo: Companhia das Letras, 2015. 